\title{
sciendo
}

\author{
RESEARCH PAPERS FACULTY OF MATERIALS \\ SCIENCE AND TECHNOLOGY IN TRNAVA \\ SLOVAK UNIVERSITY OF TECHNOLOGY \\ IN BRATISLAVA
}

2019, Volume 27, Number 45

DOI 10.2478/rput-2019-0030

\section{DIGITAL IMPLEMENTATION OF BUTTERWORTH FIRST-ORDER FILTER TYPE IIR}

\author{
Dušan HORVÁTH ${ }^{1}$, Zuzana ČERVEŇANSKÁ ${ }^{1}$, Janette KOTIANOVÁ ${ }^{1}$ \\ ${ }^{1}$ SLOVAK UNIVERSITY OF TECHNOLOGY IN BRATISLAVA, \\ FACULTY OF MATERIAL SCIENCE AND TECHNOLOGY IN TRNAVA, \\ INSTITUTE OF APPLIED INFORMATICS, AUTOMATION AND MECHATRONICS \\ UliCA JÁnA BOTTU Č. 2781/25, 91724 TRNAVA, SlOVAK REPUBLIC \\ e-mail:dusan.horvath@stuba.sk,zuzana.cervenanska@stuba.sk,janette.kotianova@stuba.sk \\ Received 27 August 2019, accepted 30 September 2019, published 29 November 2019
}

\begin{abstract}
The paper deals with the solution of the first-order passive filters (low-pass and highpass) applying electrotechnical elements (resistor, capacitor - analogue filter) and digital Butterworth filter type IIR (Infinite Impulse Response). Procedure of the filters design and implementation is described, and the analogue and digital filter outputs with the same input signal are compared. The designed filters have already served for education purposes with the intention to bring an explanation of techniques for designing required functionality of the signal processing filters.
\end{abstract}

\section{Key words}

Passive filter, resistor, capacitor, digital filter type IIR

\section{INTRODUCTION}

Frequency filters are the circuits designed to select the desired frequencies from a mixture of frequencies, output them with minimal attenuation, and retain other frequencies with maximum attenuation. To design the simplest first order passive filter, passive electronic resistor and capacitor elements are used. The passive filter transmission is maximum 1 . The advantage is a relatively simple connection. The disadvantages include the aging of components, the availability of limited component values, and the thermal dependence of components.

In modern gadgets utilising a processor, digital filters are widely applied in the electronic and telecommunication devices, e.g. in data communication and the image and sound processing. It is for the reason of a very few additional components required. They can be standardised, as they are simply software modules operating on a number of different computer platforms. They are highly flexible, able to filter very low frequencies and are adaptive to change their filter characteristics based on the input signal parameters as well. Digital filters are typically categorized into two classes: infinite impulse response type (IIR) and finite impulse 
response type (FIR). The Butterworth filter is a special type of signal processing filter referred to as a maximally flat magnitude filter. In this contribution, we deal with the design and digital implementation of the first-order Butterworth filter type IIR.

\section{OVERVIEW}

The ideal course of the amplitude-frequency characteristics of the frequency filter is shown in Figure 1.

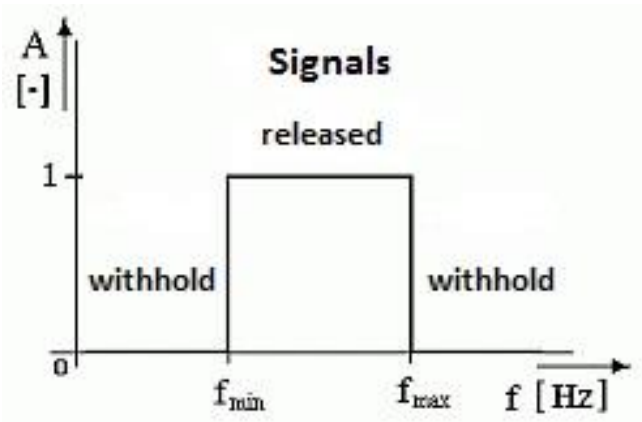

Figure 1 The ideal course of the amplitude-frequency response of the filter. Adapted from [1].

According to the frequency spectrum of the signals and the intensity of the signal attenuation, we distinguish four basic types of frequency filters [1]. They are depicted in Figure 2.

- Low-Pass Filter [LPF] transmits signals from the lowest frequencies up to a certain maximum frequency $f_{\max }$ with minimum attenuation, and all other signals with frequencies higher than $f_{\max }$, transmits with the desired attenuation.

- High-Pass Filter $[\mathrm{HPF}]$ transmits signals from a certain minimum frequency $f_{\min }$ to a theoretically infinite frequency with minimal attenuation and all other signals below frequencies below $f_{\min }$, transmits with the desired attenuation.

- Band-Pass Filter [BPF] transmits signals from a certain minimum frequency $f_{\min }$ to a certain maximum frequency $f_{\max }$ with minimum attenuation, and transmits all other signals below frequencies $f_{\min }$ and higher than $f_{\max }$ with the desired attenuation.

- Band-Stop Filter [BSF] transmits signals from a certain minimum frequency $f_{\min }$ to a certain maximum frequency $f_{\max }$ with the desired attenuation and transmits all other signals with frequencies below $f_{\min }$ and higher than $f_{\max }$ with minimal attenuation.
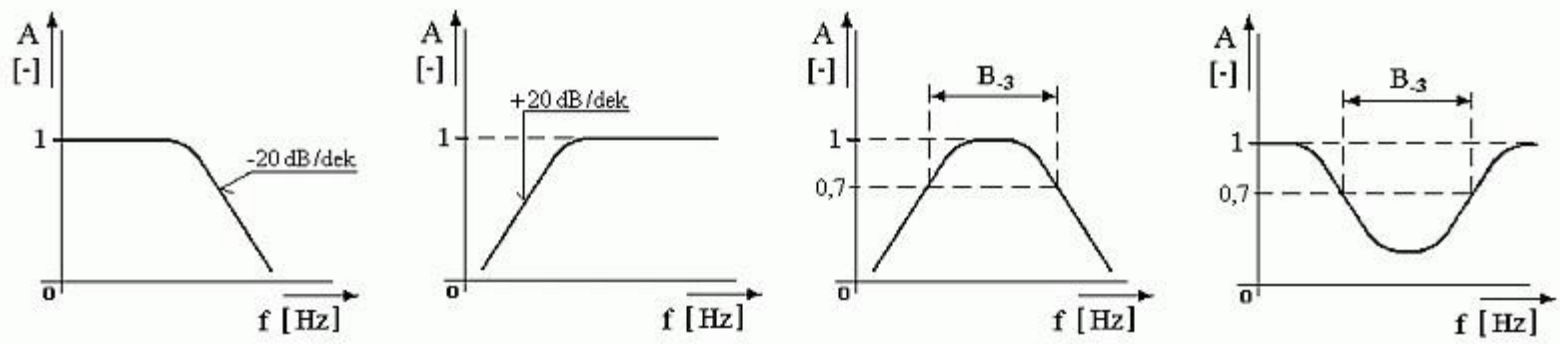

Figure 2 Transmission amplitude-frequency characteristics of individual filter types. Adapted from [1]. 
All types of these filters are made of known basic components, namely resistors, capacitors and coils. Filters are divided into four groups (see Figure 3):

- Integration cell - a low-pass filter,

- Derivative cell - a high-pass filter,

- Wien cell - a band-pass filter,

- Bridged T-cell - a band-stop filter.
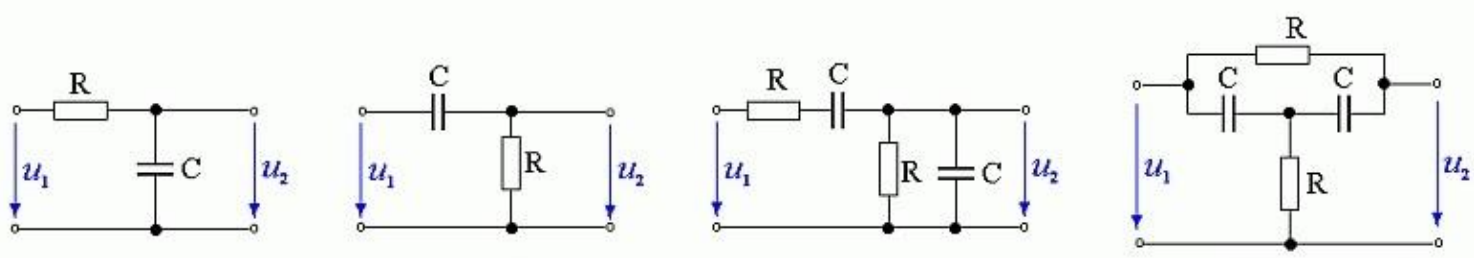

Figure 3 Connection of individual types of 1 st order filters. Adapted from [1].

Since those filters are made from the basic passive circuit components, we classify them as passive filters. Their transmission is almost equal to 1 . In addition to passive filters, active filters include except for the passive frequency dependent elements also active components (transistors, operational amplifiers) that provide the amplification of the transmitted signal. Their transmission may also be greater than 1 .

For both, passive and active filters, we distinguish so-called order of the filter. Filter order is the degree of the response approximating polynomial function, and, in passive filters, it depends on the number of reactance elements (capacitors and coils) used in the filter, that affect the transmission and amplitude-frequency properties of the filter (see Figure 4).
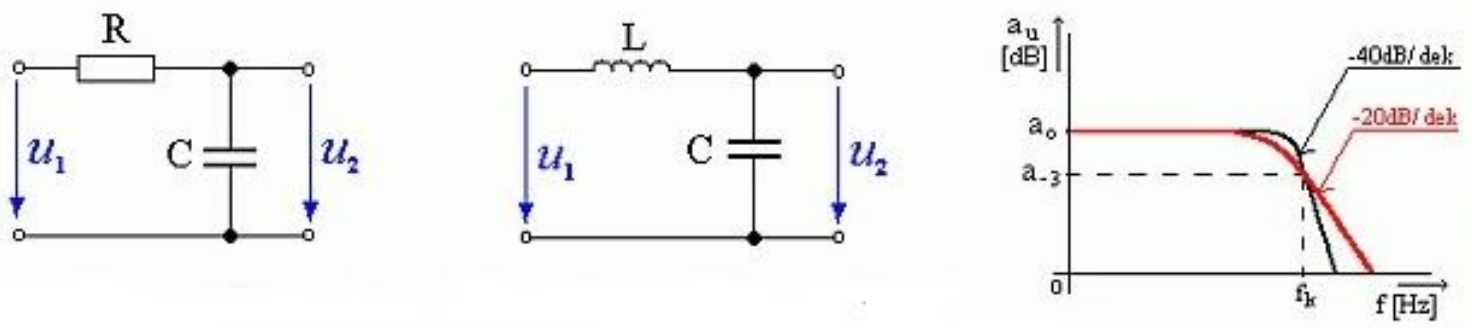

Figure 4 Passive low-pass filter of 1 st and 2nd order and their transmission characteristics. Adapted from [1].

The first order low-pass filter contains only one reactive element, so its transmission amplitude-frequency characteristics shows a slope of $-20 \mathrm{~dB} /$ decade. The low-pass filter of the 2 nd order contains two reactive elements (capacitor and coil), so its transmission amplitudefrequency characteristics shows a slope of $-40 \mathrm{~dB} /$ decade (Figure 4 ). Increasing order increases roll-off and brings the filter closer to the ideal response.

\section{RESULTS - IMPLEMENTATION OF THE FIRST-ORDER PASSIVE FILTERS}

\section{The first-order analogue filter}

The scheme of the connection is in Figure 6. Resistors $R_{1}$ and $R_{2}$ both serve as a resistive divider. Value $R_{1}=10 \mathrm{k} \Omega, R_{2}=10 \mathrm{k} \Omega$. The pulse-width modulation (PWM) input signal has a voltage of $+3.3 \mathrm{~V}$. The capacitor value $C_{1}=100 \mathrm{nF}$. The PWM signal frequency is $50 \mathrm{~Hz}$ and 
is the sampling period is $10 \mathrm{kHz}$. The capacitor $C_{1}$ in the circuit in Figure 5 and Figure 6 is identical, and the scheme in Figure 6 shows its function as a filter for higher frequencies. The capacitor reactance decreases with the increasing frequency. The rectangular signal can be composed using odd sinusoidal harmonics. The rectangular signal is in fact a sine signal cluster with the first harmonic frequency being the frequency of the rectangular signal. The filter cutoff frequency is the signal frequency at which the signal amplitude/output ratio is 0.707 ( $3 \mathrm{~dB}$ attenuation). The cut-off frequency of the RC cell is calculated by the formula (1)

$$
f_{0}=1 /(2 \pi R C) .
$$

In Figure 6, the frequency is given as $f_{0}=1 /\left(2 \pi R_{1} C_{1}\right)=159 \mathrm{~Hz}$, as described in [2]. Figure 7 and Figure 8 illustrate the filtered signal at the output of low-pass and high pass first-order analogue filter with a detail of the rising and falling edges of the input PWM signal.
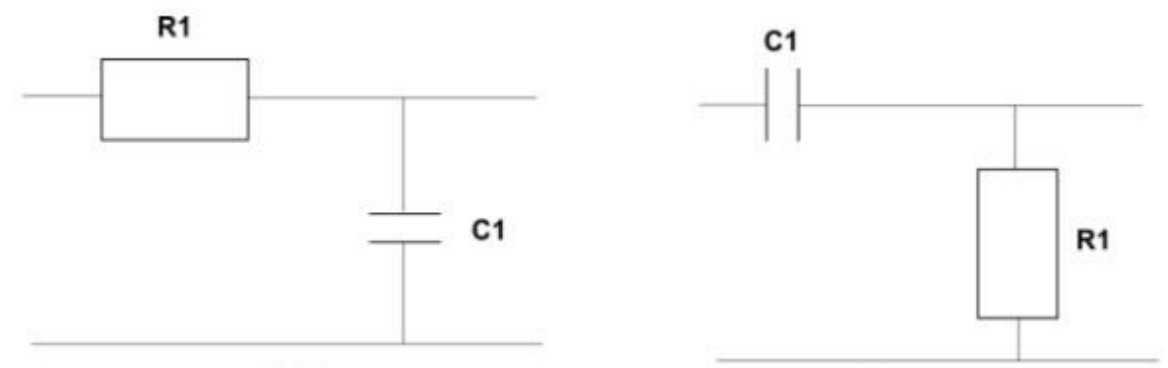

Figure 5 The analogue filter connection for the first-order low-pass and high-pass filter type. Adapted from [1].

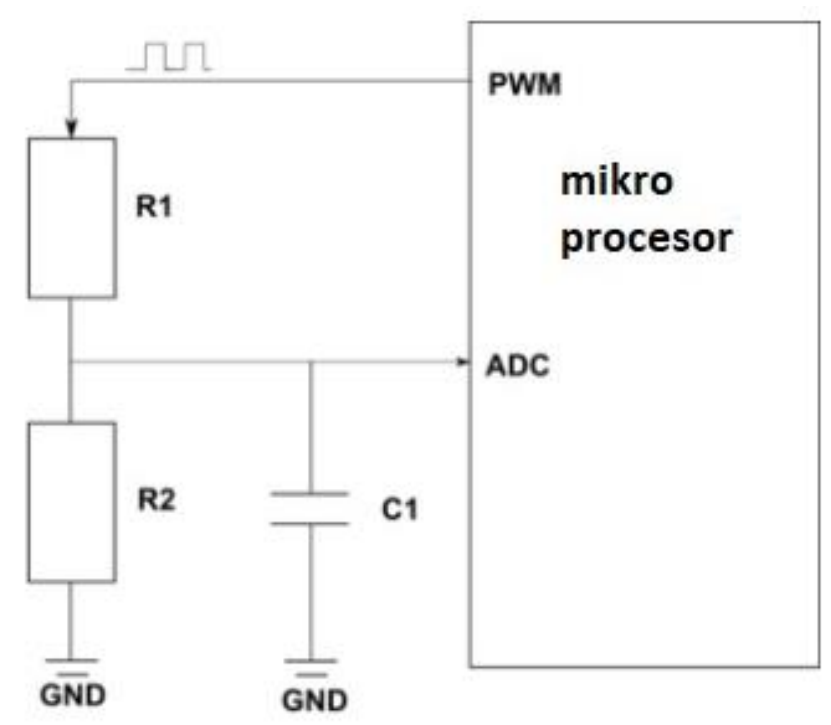

Figure 6 A scheme for generation of rectangular PWM signal for an analogue filter LPF of the 1st order. Adapted from [2]. 


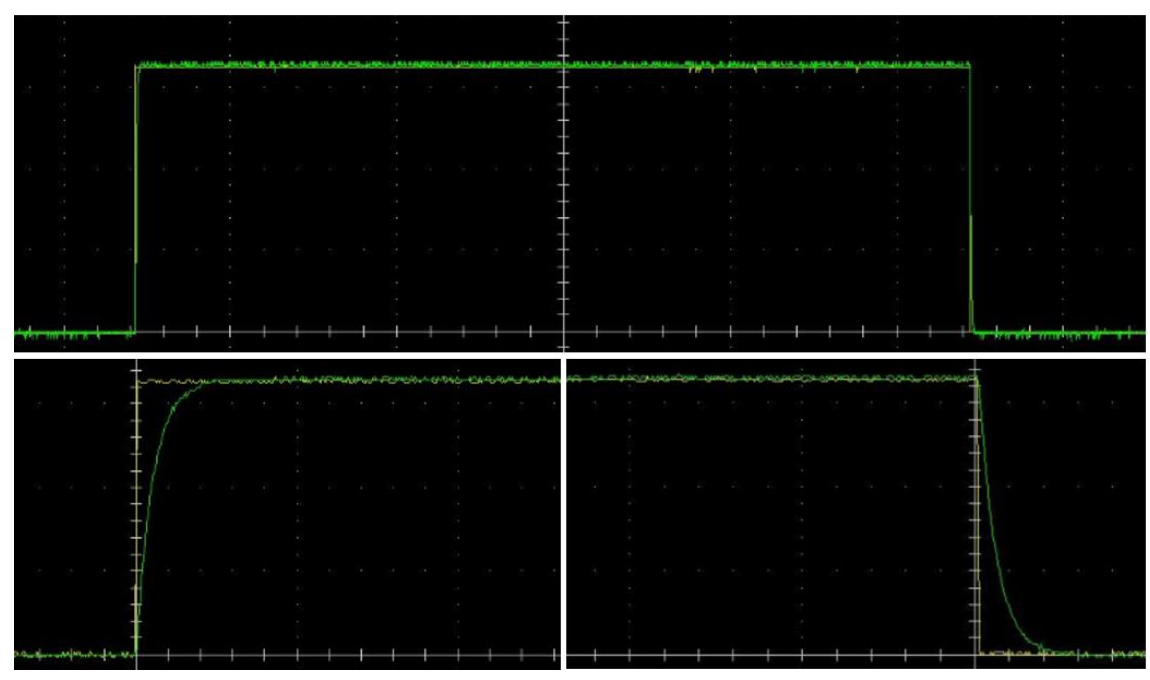

Figure 7 The filtered signal at the output of low-pass first-order analogue filter (the upper graph has a time base $2 \mathrm{~ms}$ ), detail of the rising and falling edges of the input PWM signal are shown in the lower parts of the Figure (a time base $100 \mathrm{~ns}, 1 \mathrm{~V} / \mathrm{div}$ )

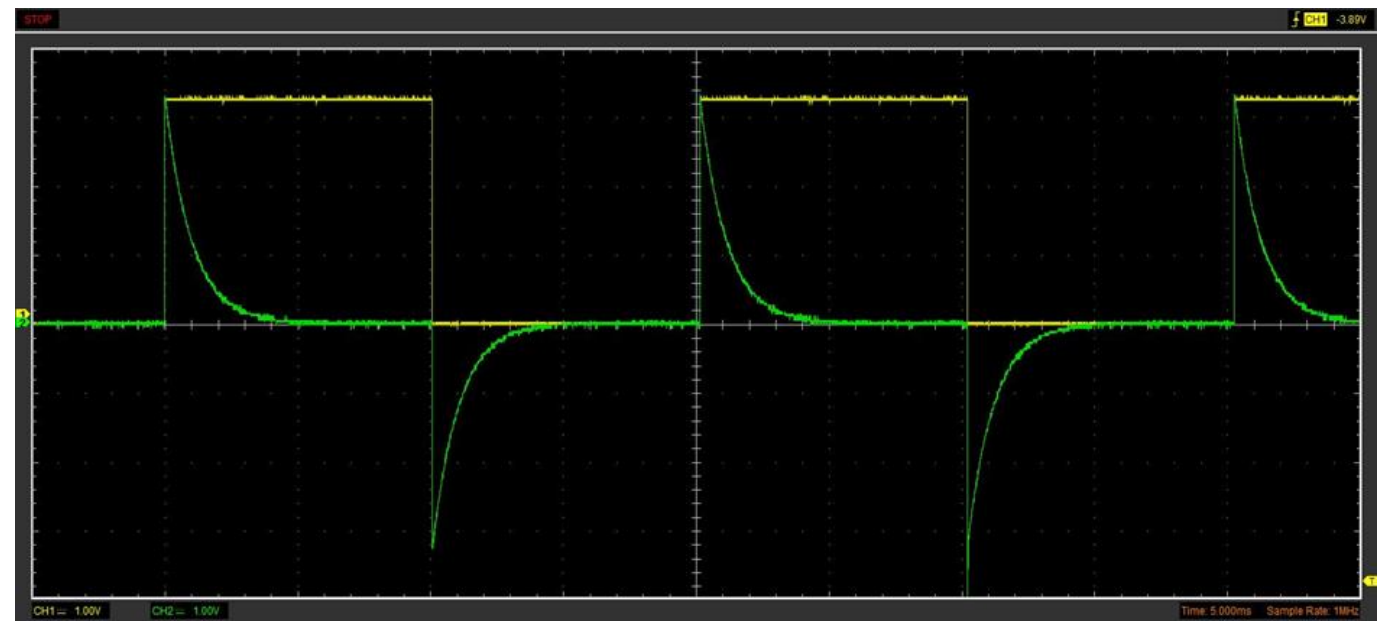

Figure 8 The filtered signal waveform at the output of the high-pass first-order analogue filter (a time base $5 \mathrm{~ms}, 1 \mathrm{~V} / \mathrm{div}$ )

\section{The first order Butterworth digital filter}

The transfer function $H(\mathrm{~s})$ of the first order low-pass and high-pass filter is given by equation (2):

$$
H(\mathrm{~s})=\omega_{c} /\left(\mathrm{s}+\omega_{c}\right)
$$

where $\omega_{c}$ is cut-off frequency, $\omega_{c}=2 \pi f_{0}$. This transfer function should be given in a discrete form [3]. There are a large number of techniques which are applied to design IIR filters belonging to discrete linear filters. The applied procedure of finding bilinear transform equivalent of transfer function and further applying the inverse $\mathrm{z}$ - transform is described in detail in [3]. The result is the difference equation of the low-pass and high-pass filter of the first order in the discrete form (3):

$$
y(n)=b_{1} \cdot x(n)+b_{2} \cdot x(n-1)-\mathrm{a}_{2} \cdot y(n-1),
$$

where $y(n)$ represents a current value at filter output, $x(n)$ is a current value at filter input, 
$y(n-1)$ is a previous filter output value, and $x(n-1)$ is a previous filter input value. Parameters $b_{1}, b_{2}$ and $a_{2}$ are filter coefficients that are calculated according to [3]. To calculate the coefficients for the low-pass filter, we use the relations (4) - (6):

$$
\begin{aligned}
& b_{1}=2 \tan \left(\omega_{\mathrm{D}} T / 2\right) /\left[2+2 \tan \left(\omega_{\mathrm{D}} T / 2\right)\right] \\
& b_{2}=2 \tan \left(\omega_{\mathrm{D}} T / 2\right) /\left[2+2 \tan \left(\omega_{\mathrm{D}} T / 2\right)\right] \\
& \left.a_{2}=\left[2 \tan \left(\omega_{\mathrm{D}} T / 2\right)-2\right] /\left[2+2 \tan \left(\omega_{\mathrm{D}} T / 2\right)\right]\right],
\end{aligned}
$$

where $\omega_{D}=2 \pi f_{D}$ is the cut-off frequency in [rad/s] and $T$ is the sampling period in [s]. The cutoff frequency of the analogue filter $\omega_{c}$ must be shifted relative to the digital filter cut-off frequency $\omega_{D}[3]$ according to (7):

$$
\omega_{c}=(2 / \mathrm{T}) \tan \left(\omega_{\mathrm{D}} T / 2\right) \text {. }
$$

To calculate coefficients for the high-pass filter, we use the relations (8)-(10) derived in [3]:

$$
\begin{aligned}
& b_{1}=2 /\left[2+2 \tan \left(\omega_{\mathrm{D}} T / 2\right)\right] \\
& b_{2}=-2 /\left[2+2 \tan \left(\omega_{\mathrm{D}} T / 2\right)\right] \\
& \left.a_{2}=\left[2 \tan \left(\omega_{\mathrm{D}} T / 2\right)-2\right] /\left[2+2 \tan \left(\omega_{\mathrm{D}} T / 2\right)\right]\right] .
\end{aligned}
$$

\section{Hardware and software implementation}

Using a timer, we generate a $50 \mathrm{~Hz}$ and a $50 \%$ duty cycle PWM signal. This PWM signal is scanned by the ADC converter (Figure 9). Value $R_{1}=10 \mathrm{k} \Omega, R_{2}=10 \mathrm{k} \Omega$. The ADC converter samples at frequency $10 \mathrm{kHz}$. The measured values are saved to the microprocessor memory field, and then we calculate the current filter output value applying the development microprocessor kit Cypress PSoC6 (Figure 10, Figure 11). After measuring and filtrating 512 samples, we send them through the serial port to the PC, and then display the measured and filtered signal in the Excel spreadsheet.

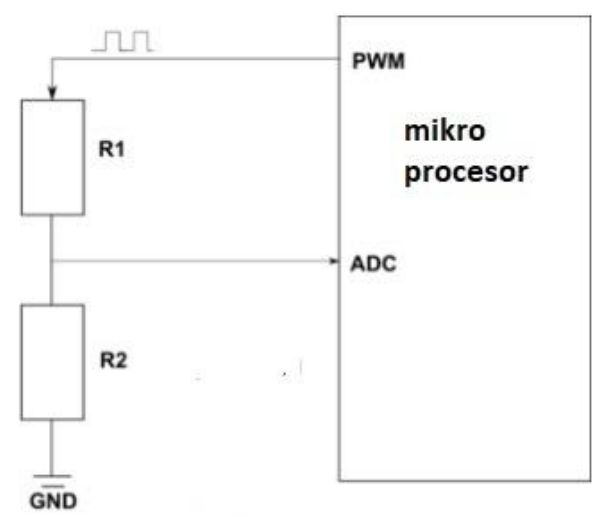

Figure 9 Generation of the PWM signal for the digital filter of the low-pass and the high-pass type of the first order. Adapted from [2].

The development kit parameters (Figure 10) were as follows:

- 150-MHz ARM Cortex-M4F + 100-MHz Cortex M0 +,

- ADC 8-12 bit,

- core supply voltage optionally $1.1 \mathrm{~V}$ or $0.9 \mathrm{~V}$, chip power supply $1.7 \mathrm{~V}$ to $3.6 \mathrm{~V}$,

- 1MB FLASH with 32kB EEPROM, Read-While-Write update; 288kB SRAM with $32 \mathrm{kB}$ battery backed up, 
- 2x 16-channel DMA, 9 configurable serial interfaces, 32 timer blocks (16-bit),

- Cases BGA-116, MCSP-104,

- Bluetooth BLE 4.2.

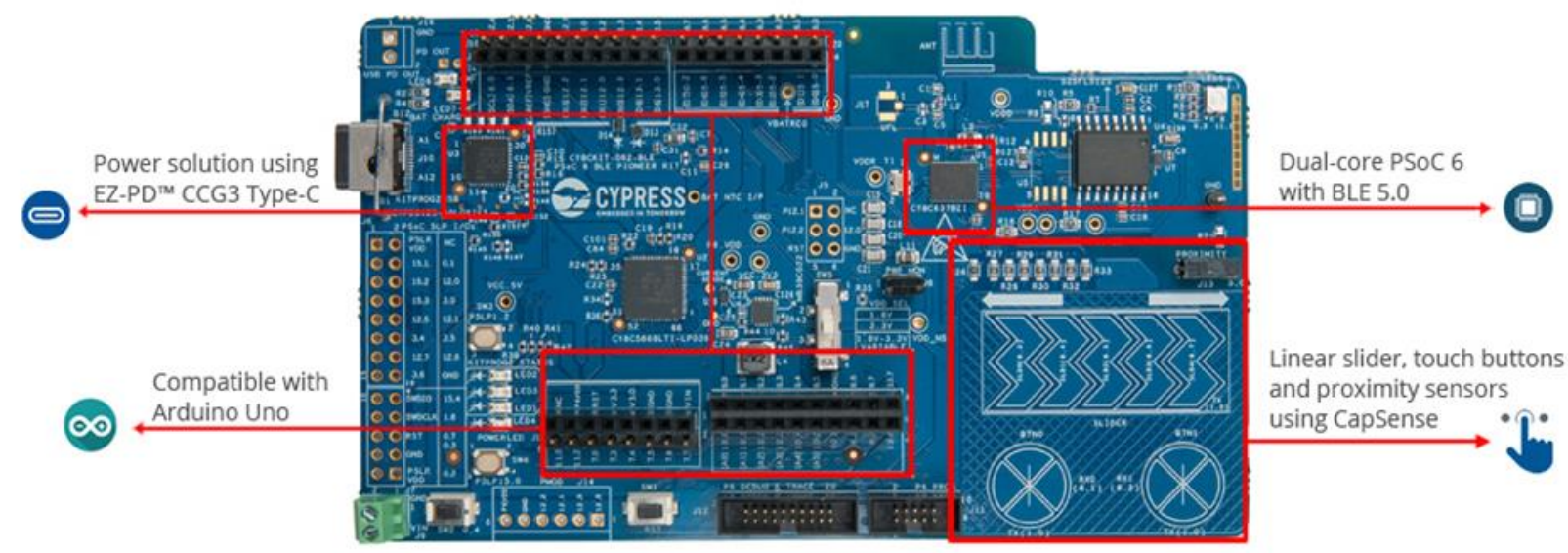

Figure 10 Cypress PSoC6 development microprocessor kit. Adapted from[4].

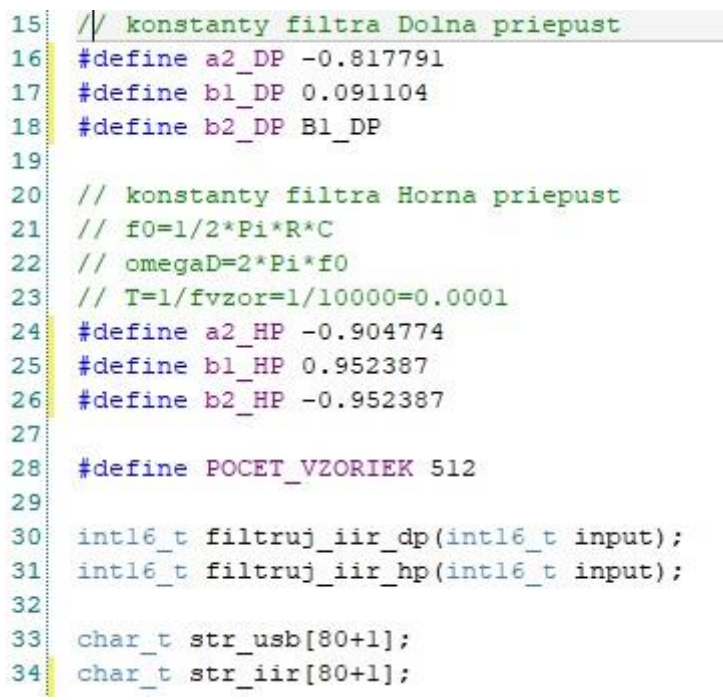

Figure 11 A part of the source code with constants $a_{2}, b_{1}$ and $b_{2}$ for the low-pass and the high-pass digital filter of the first order

\section{DISCUSSION ON RESULTS}

The attained results of applying the low-pass and high-pass digital filters of the first-order on PWM input signal are shown as Excel graphic outputs in Figure 12 and Figure13. The Figures depict the signal flow at the output of the specific filters in comparison to the input PWM signal. As can be seen in Figures 7, 8, 12 and 13, the input rectangular signal can be filtered by applying the Butterworth digital filter as well as using an analogue filter. We can see that the filtered output signals are the same. The advantage of digital filters is that they are easy to retune to a different frequency by a relatively simple calculation of input parameters (eq. 4 to 9). They do not suffer from drift; they are stable with respect to both time and temperature. In addition, higher order filters and filters which would be difficult to construct using analogue components can be easily designed. Compared to analogue filters, the utilisation of digital filters is influenced by some of disadvantages mentioned in [5]: the price, the fact that the signal bandwidth of the input signal is limited by ADC and DAC and also, the bandwidth of the digital filter is much lower than an analogue filter. Another fact is that the accuracy of the digital filter 
depends on the word length used to encode them in binary form and it requires more design and development time compared to an analogue filter, and the quantization noise is present.

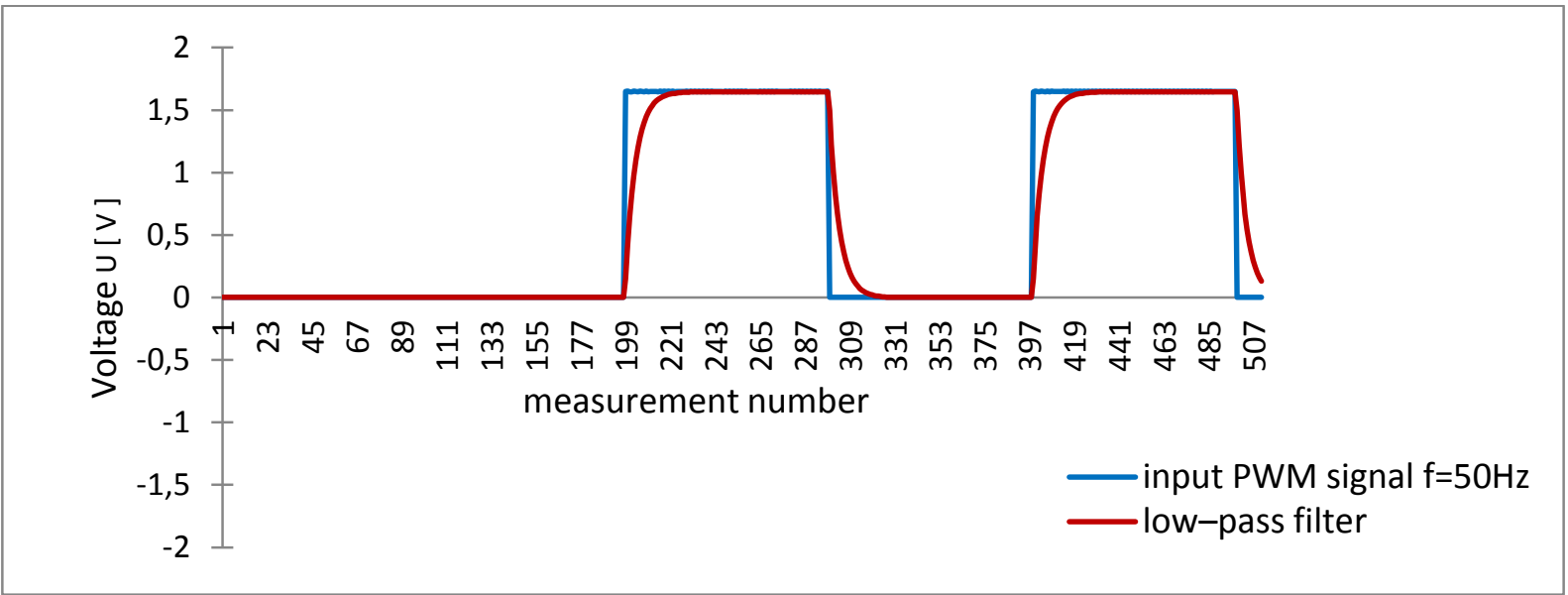

Figure 12 Signal flow at the output of the low-pass digital filter of 1 st order

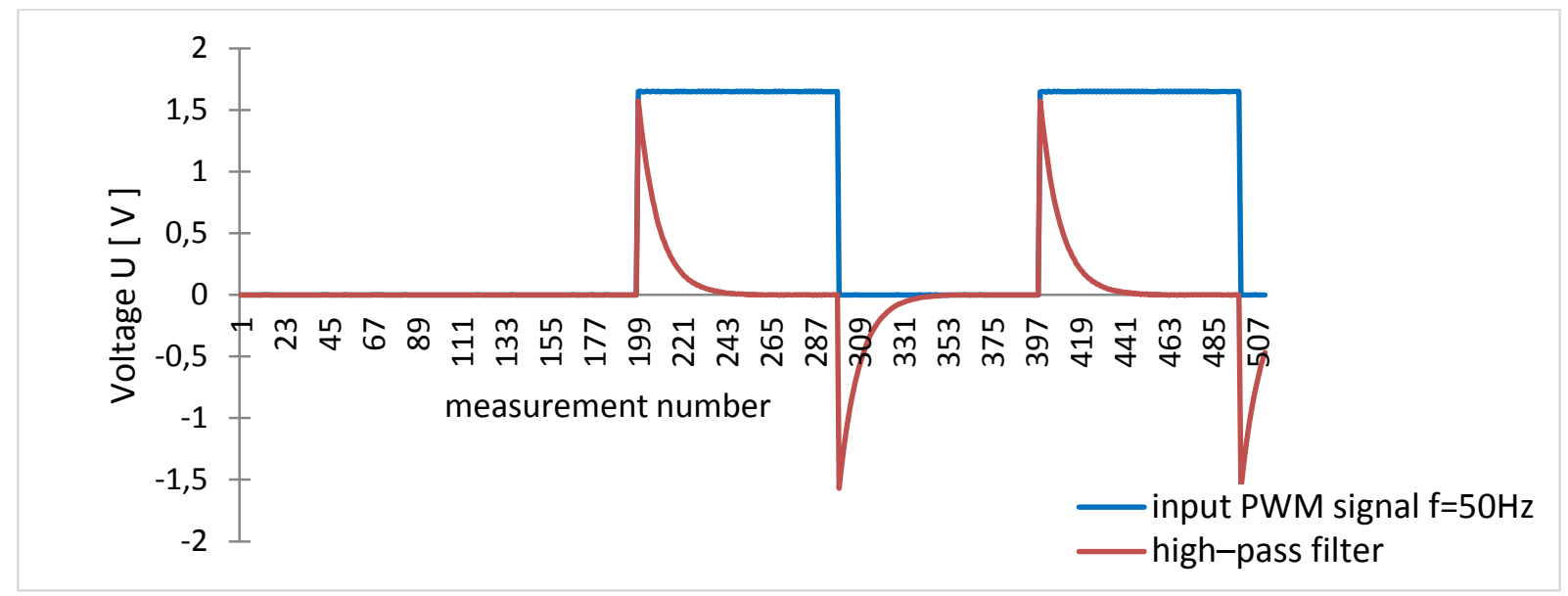

Figure 13 Signal flow at the output of the high-pass digital filter of 1st order

\section{CONCLUSION}

To present and explain the functionality and theoretical background for using frequency filters in the education within the subject of "Automation of Data Acquisition and Processing", the passive analogue filter and the Butterworth first-order digital filter type IIR was designed using Cypress PSoC6 development microprocessor kit. Comparing the output signals according to the applying analogue and a designed first-order digital filter, we found that an input of rectangular signal can be filtered similarly to using an analogue filter, and the output signals are identical. Therefore, students can compare them and find that digital filters of the first order are useful components for signal processing.

\section{Acknowledgement}

This paper was partially supported by the International Visegrad Fund under Strategic Grant No. 21810100, V4+ Academic Research Consortium for the integration of databases, robotics and language technologies. 
This publication has been written thanks to support of the Operational Program Research and Innovation for the project: Research of advanced methods of intelligent information processing ITMS code: NFP313010T570 co-financed by the European Regional Development Fund.

\section{References}

[1] Frekvenčné selektory (Frequency Selectors). [Online]. [Accessed: 06-2019] Available at https://alzat.spseke.sk/selektory/frekvenc/frek_sel.htm

[2] Pokročilé programovanie mikropočítačov v jazyku C. - Diel č.3 (Advanced microcomputer programming in C. Part 3) [Online]. [Accessed: 05-2019] Available at https://svetelektro.com/clanky/pokrocile-programovanie-mikropocitacov-v-jazyku-c-diel-c-3785.html

[3] MIENKINA, M. 2016. Filter-Based Algorithm for Metering Applications [Online]. [Accessed: 062019] Available at https://www.nxp.com/docs/en/application-note/AN4265.pdf

[4] PSoC6 development microprocessor kit. [Online]. [Accessed: 05-2019] Available at http://www.cypress.com/documentation/development-kitsboards/psoc-6-ble-pioneer-kit

[5] ECSTUFF4U for Electronics Engineer. Advantages and disadvantages digital filter. [Online]. [Accessed: 06-2019] Available at https://www.ecstuff4u.com/2018/01/digital-filter-advantagesand.html

\section{ORCID}

Dušan Horváth

0000-0002-9647-4627

Zuzana Červeňanská

0000-0002-6380-4634

Janette Kotianová

0000-0003-2105-3155 